\title{
UTILIZAÇÃO DA FULIGEM DE BAGAÇO DE CANA-DE- AÇÚCAR COMO ADSORVENTE DE POLUENTES ORGÂNICOS
}

\author{
F. A. CALVI, A. C. STENICO, R. L. ZORNITTA e L. A. M. RUOTOLO \\ Universidade Federal de São Carlos, Departamento de Engenharia Química \\ E-mail para contato: felipe.antunes@live.com
}

\begin{abstract}
RESUMO - Um meio viável e barato para o tratamento de águas residuais de refinarias de petróleo é o uso da fuligem proveniente da queima do bagaço de cana-de-açúcar, que está disponível em grandes quantidades no país. Tais efluentes possuem diversos poluentes orgânicos nocivos ao meio ambiente e à saúde humana. Buscou-se o desenvolvimento de um material natural de baixo custo capaz de adsorver compostos orgânicos, estudando-se as capacidades de adsorção de fenol pela fuligem submetida a diferentes tratamentos químicos, com a finalidade do tratamento de um efluente real, fornecido por uma refinaria de petróleo nacional. A fuligem utilizada neste trabalho foi submetida a tratamentos químicos com ácido sulfúrico e hidróxido de sódio a fim de remover impurezas que poderiam estar bloqueando o acesso aos poros e aos sítios ativos do adsorvente. A partir das curvas de ruptura foi possível calcular a quantidade adsorvida de fenol, estudada em função da temperatura do processo e dos tratamentos químicos utilizados. Concluiu-se que esse material tem grande capacidade de adsorção de fenol ( $\sim 4 \mathrm{mg}$ fenol/mg fuligem) e para a adsorção de um efluente real mostrou-se um material bastante promissor uma vez que foi possível remover uma grande quantidade da carga orgânica do efluente, pois houve uma diminuição de $67 \%$ da demanda química de oxigênio (DQO) em apenas 5 minutos de experimento.
\end{abstract}

\section{INTRODUÇÃ̃O}

Atualmente, cerca de $80 \%$ do consumo de energia mundial vem da queima de combustíveis fósseis e este número vem aumentando em cerca de $2 \%$ ao ano, sendo ainda um recurso esgotável. Visando evitar um problema futuro, cientistas do mundo todo vêm desenvolvendo novas formas de energia provenientes de fontes renováveis, não só devido à exaustão das reservas fósseis, mas também pelos efeitos negativos à natureza por seu uso excessivo (Goldemberg et al., 2008).

O Brasil é o país que reúne mais vantagens comparativas para liderar a produção de bioenergia, sendo o Estado de São Paulo, atualmente, referência global no cultivo e na produção de derivados de cana-de-açúcar e o segundo maior produtor mundial de etanol. Porém, como resíduo do processo de produção do etanol são gerados resíduos como, por exemplo, a fuligem, oriunda da queima do bagaço para geração de vapor e energia elétrica nas 


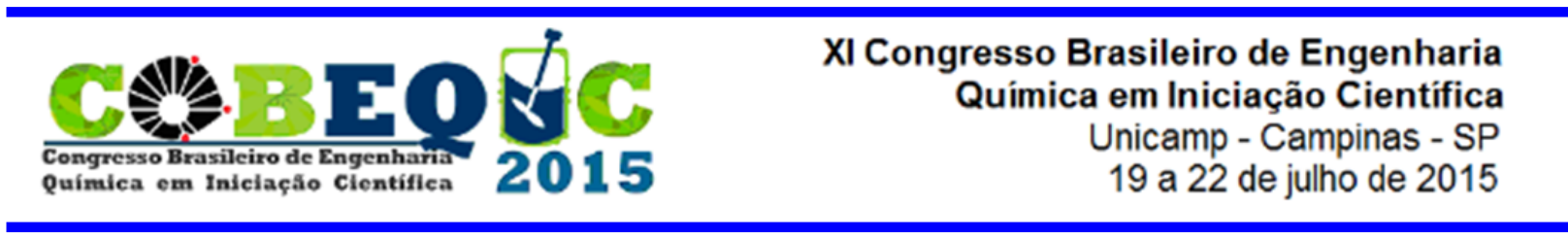

próprias usinas (Tavares, 2013). Essa fuligem, composta principalmente de carbono, algumas vezes é utilizada como adubo ou então é descartada (Ribeiro, 2008).

O objetivo deste projeto é utilizar a fuligem, proveniente da queima do bagaço da canade-açúcar, para o tratamento de águas residuais das usinas de petróleo, que geram diariamente efluentes orgânicos com diversos poluentes e materiais tóxicos, nocivos ao meio ambiente. Um meio viável e barato para o tratamento desses efluentes das indústrias seria o uso dessa fuligem. Neste contexto, busca-se o desenvolvimento de um material, utilizando a fuligem do bagaço de cana, capaz de adsorver compostos orgânicos. A capacidade deste material para adsorver compostos orgânicos foi analisada através experimentos de adsorção de fenol, por ser essa uma molécula modelo e também por ser um composto comum em efluentes industriais.

\section{MATERIAIS E MÉTODOS}

\subsection{Materiais}

Fenol: As soluções de fenol (Sigma-Aldrich) foram preparadas utilizando-se água deionizada. Por ser corrosivo e fatal se ingerido ou inalado, o fenol é proibido de ser descartado diretamente na natureza. Por estar presente em diversos efluentes industriais, essa molécula foi escolhida para os experimentos de adsorção.

Fuligem: A fuligem utilizada era proveniente da queima do bagaço da cana-de-açúcar, e foi coletada na base do lavador de gases da caldeira da Usina Califórnia, situada na cidade de Parapuã, estado de São Paulo.

Ácidos e bases: Foram realizados tratamentos ácidos e básicos na fuligem com a finalidade de comparação. Utilizou-se soluções aquosas de ácido sulfúrico (Synth) com concentração de 1,0 mol L-1 e hidróxido de sódio (Mallinckrodt) com concentração de 3,5 mol L-1.

Efluente real: $\mathrm{O}$ efluente utilizado neste projeto foi fornecido por uma refinaria de petróleo nacional situada no estado de São Paulo. O efluente era proveniente da água fenólica dos filtros de sal, cuja concentração de fenóis totais é de aproximadamente 22000 ppm e seu $\mathrm{pH}$ é de 10,4. O efluente foi devidamente filtrado para remover os sólidos em suspensão antes de sua utilização na coluna de adsorção. Após a filtração, a demanda química de oxigênio (DQO) do efluente era de 7300.

\subsection{Coluna de adsorção}

Utilizou-se uma coluna de adsorção, conforme ilustrado na Figura 1, com 4,7 mm de diâmetro e altura de $30 \mathrm{~mm}$, sendo a massa de adsorvente empregada de 0,15 $\mathrm{mg}$ e 0,13 $\mathrm{mg}$ para utilização nos experimentos em que se estudou o efeito da temperatura e os diferentes tipos de tratamento, respectivamente. A solução permeava pela coluna, da base para o topo, com o auxílio de uma bomba peristáltica ajustada para fornecer uma vazão de $0,55 \mathrm{~mL} \mathrm{~min}{ }^{-1}$. Na saída da coluna, o adsorbato passava por uma cubeta de fluxo e a absorbância era medida on line, a cada 5 s, em um espectrofotômetro UV-Visível (Ultrospec2100Pro, AmershamPharmacia). 


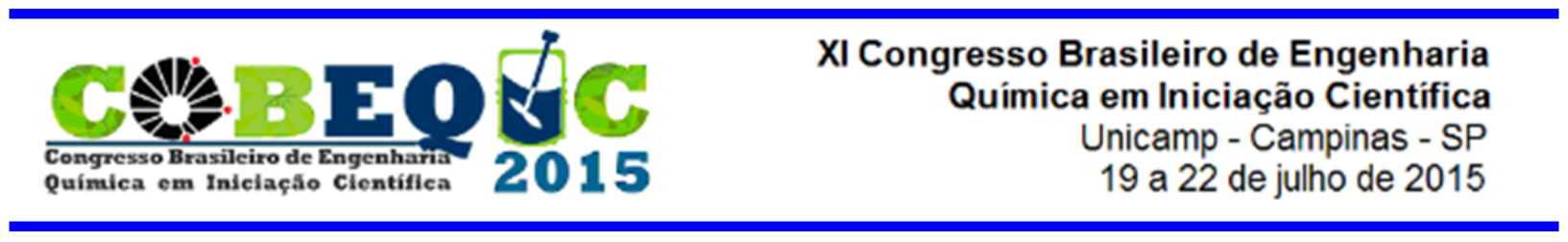

Figura 1 - Representação esquemática da coluna e do sistema usados para adsorção.

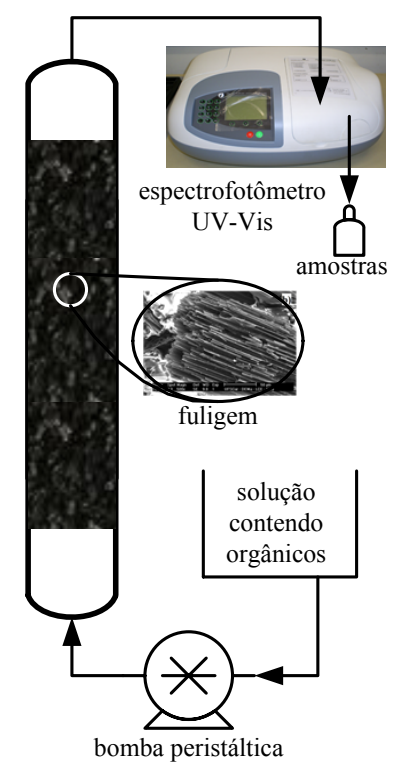

\subsection{Metodologias}

Preparação da fuligem: Resultados preliminares mostraram que o tratamento da fuligem com ácido sulfúrico, quando comparado com os ácidos nítrico e clorídrico, apresentava os melhores resultados para a adsorção de fenol. Portanto, esse tratamento ácido foi escolhido para ser utilizado neste trabalho. Também foi estudado o efeito de um tratamento alcalino da fuligem. Ambos os tratamentos ocorreram de forma semelhante em um sistema de refluxo montado com um balão de fundo redondo de $125 \mathrm{~mL}$ acoplado a um condensador para evitar a perda da solução. Neste balão foi adicionado $1,0 \mathrm{~g}$ de fuligem e $60 \mathrm{~mL}$ das soluções de ácido sulfúrico ou hidróxido de sódio. O balão foi colocado em uma manta de aquecimento, que foi ajustada até que a temperatura atingisse o ponto de ebulição da mistura. Deixou-se a mistura em refluxo por uma hora. A seguir, a fuligem foi filtrada a vácuo e lavada com aproximadamente $1 \mathrm{~L}$ de água deionizada. Por fim, a fuligem foi seca em estufa a $100^{\circ} \mathrm{C}$, por 24 horas.

Obtenção das curvas de ruptura para a fuligem: A coluna de adsorção mostrada na Figura 1 foi preenchida com a fuligem de acordo com o descrito na seção 2.2. Em cada experimento foi utilizada uma solução com concentração de aproximadamente $50 \mathrm{mg} \mathrm{L}^{-1} \mathrm{de}$ fenol.

Obtenção das curvas de ruptura para o efluente real: Após selecionada a melhor fuligem e a melhor condição experimental, o mesmo procedimento adotado para a adsorção do fenol foi realizado para efluente real. Porém, neste caso, a coluna foi preenchida com $0,2922 \mathrm{~g}$ de fuligem, resultando em uma altura de $82,5 \mathrm{~mm}$. Na saída da coluna, foram coletados aproximadamente $2,0 \mathrm{~mL}$ de adsorbato em períodos de 4 minutos, durante uma hora, para depois ser analisado no espectrofotômetro UV-Visível na faixa de comprimento de onda de 190 e $900 \mathrm{~nm}$. Mediu-se também a DQO.

DQO: Como o efluente real constitui-se de uma mistura complexa de muitos compostos orgânicos, a eficácia de adsorção da fuligem foi avaliada também em termos da 
remoção da DQO, determinada através da técnica de oxidação de compostos orgânicos por dicromato. O método mede a concentração de matéria orgânica oxidada. A DQO foi realizada com uma diluição de 100 vezes do efluente em água destilada.

\section{RESULTADOS E DISCUSSÕES}

\subsection{Curvas de ruptura para a adsorção do fenol}

As curvas de ruptura para a adsorção de fenol para diferentes temperaturas e tipos de tratamento são mostradas na Figura 2(a) e 2(b), respectivamente. Na Figura 2(a) é possível verificar que o tempo de ruptura $\left(t_{\mathrm{r}}\right)$, ou seja, o tempo em que se observa o aumento da concentração de fenol na saída da coluna, foi maior quando se trabalhou com temperaturas menores. Através da curva de ruptura foi possível calcular a quantidade de fenol adsorvido na coluna desde o início da operação até o tempo $t_{r}$. A quantidade de fenol adsorvido é mostrada na Tabela 1.

Figura 2 - Concentração normalizada de fenol em função do tempo: (a) para diferentes temperaturas usando fuligem com tratamento ácido e (b) para diferentes tratamentos $\left(23^{\circ} \mathrm{C}\right)$.

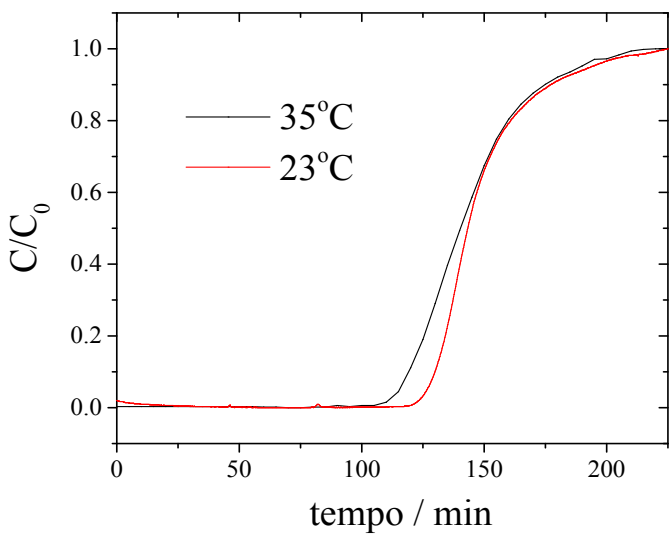

(a)

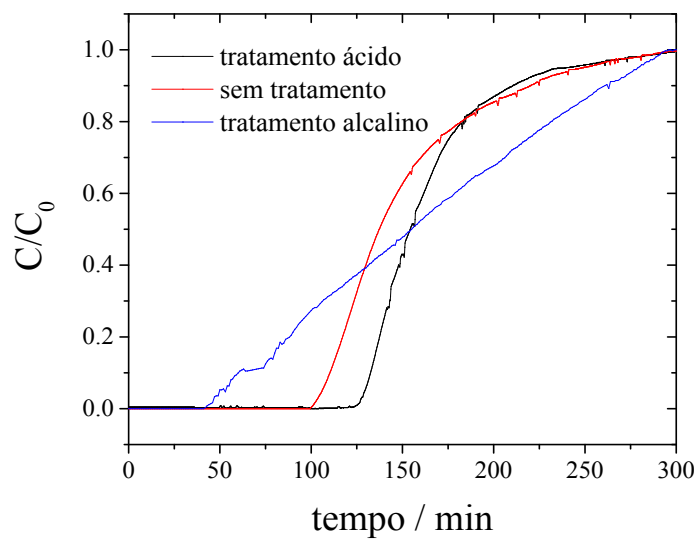

(b)

Tabela 1 - Quantidade de fenol adsorvido na coluna em função da temperatura.

\begin{tabular}{cccc}
\hline Temperatura $\left({ }^{\circ} \mathbf{C}\right)$ & $\mathbf{t}_{\mathbf{r}}(\mathbf{m i n})$ & $\begin{array}{c}\text { Volume de fenol } \\
\text { tratado }(\mathbf{m L})\end{array}$ & $\begin{array}{c}\text { Quantidade de fenol } \\
\text { adsorvido }(\mathbf{m g})\end{array}$ \\
\hline $\mathbf{3 5}$ & 105 & 57,75 & 2,31 \\
\hline $\mathbf{2 3}$ & 117 & 64,35 & 2,57 \\
\hline
\end{tabular}

A quantidade de fenol adsorvido aumentou conforme se diminuiu a temperatura, indicando que o processo é exotérmico e que as moléculas adsorvidas possuem um alto grau vibracional e são, portanto, susceptíveis de dessorção da superfície em temperaturas maiores (Cooney, 1998). Assim, o aumento da temperatura causou uma diminuição da capacidade de adsorção, conforme a Figura 2(a). Diante deste resultado, todos os demais experimentos foram realizados à temperatura ambiente $\left(\sim 23^{\circ} \mathrm{C}\right)$. 


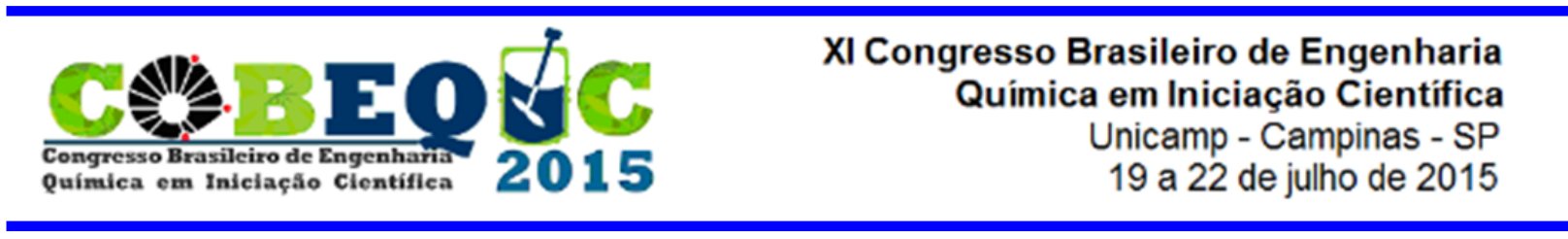

Com a finalidade de verificar se um tratamento alcalino poderia provocar uma melhoria do processo de adsorção, comparou-se na da Figura 2(b) a adsorção usando a fuligem sem tratamento e com os tratamentos ácido e alcalino. Na Tabela 2 são mostrados os resultados de quantidade de fenol adsorvido em função do tipo de tratamento.

Tabela 2 - Quantidade de fenol adsorvido em função dos tipos de tratamento utilizados.

\begin{tabular}{cccc}
\hline Tipo de tratamento & $\mathbf{t}_{\mathbf{r}}(\mathbf{m i n})$ & $\begin{array}{c}\text { Volume de fenol } \\
\text { adsorvido }(\mathbf{m L})\end{array}$ & $\begin{array}{c}\text { Quantidade de fenol } \\
\text { adsorvido }(\mathbf{m g})\end{array}$ \\
\hline Ácido $\left(\mathrm{H}_{\mathbf{2}} \mathbf{S O}_{\mathbf{4}}\right)$ & 123 & 67,65 & 2,71 \\
\hline Sem tratamento & 99 & 54,45 & 2,18 \\
\hline Básico $(\mathbf{N a O H})$ & 40 & 22 & 0,88 \\
\hline
\end{tabular}

A quantidade de fenol adsorvido na coluna dependeu do tipo de tratamento realizado na fuligem. No caso da fuligem sem tratamento, verificou-se que o seu desempenho para adsorção foi pior do que para a fuligem sem tratamento ácido, no entanto foi bastante superior ao resultado obtido com a fuligem submetida ao tratamento alcalino.

Nota-se na Figura 2 que a cinética de adsorção sofre influência da temperatura, mas mais intensamente do tipo de tratamento utilizado. O aumento da temperatura causa uma diminuição da cinética de adsorção. No caso do tipo de tratamento, não é possível notar uma diferença expressiva entre as cinéticas de adsorção entre as fuligens natural e aquela com tratamento ácido, no entanto, por outro lado, o tratamento básico leva a uma grande diminuição da cinética e a saturação da coluna só é atingida decorrido um grande tempo após atingido o tempo de ruptura.

\subsection{Adsorção de compostos orgânicos de um efluente real}

Com a finalidade de testar a eficácia da fuligem para o tratamento de um efluente real, foram feitos experimentos de adsorção usando o efluente real. Com base nos resultados anteriores, esse experimento foi realizado em temperatura ambiente $\left(23^{\circ} \mathrm{C}\right)$, utilizando a fuligem tratada com $\mathrm{H}_{2} \mathrm{SO}_{4}$. Para comprovar e quantificar a eficácia da adsorção foram realizadas análises de DQO, cujos resultados são mostrados na Figura 3(a). Verifica-se que a coluna torna-se praticamente saturada depois de aproximadamente $5 \mathrm{~min}$ de experimento. Passados 10 min, a coluna já se encontrava praticamente saturada e não era possível observar uma remoção de DQO. A Figura 3(b) mostra uma fotografia das amostras na saída da coluna em diferentes intervalos de tempo, onde é possível confirmar visualmente que houve a adsorção dos compostos orgânicos do efluente.

Figura 3 - (a) DQO em função do tempo para a adsorção do efluente real (diluição de 100 vezes). (b) Fotografia do efluente real na saída da coluna para as amostras coletados nos 


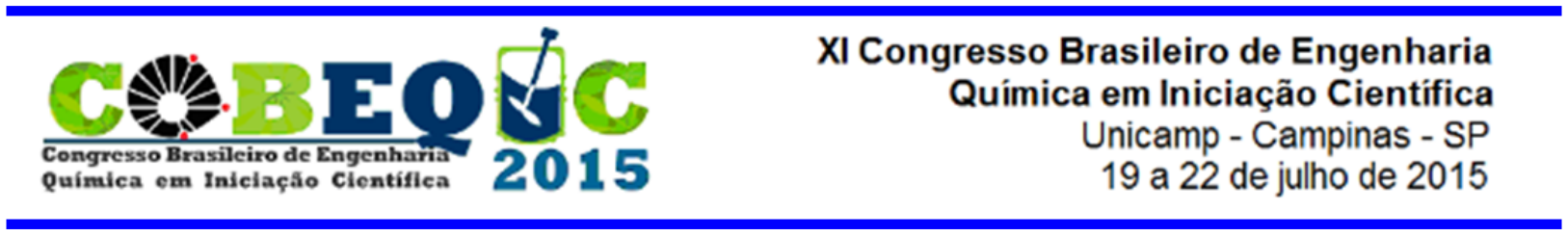

seguintes intervalos de tempo: 1) entre 0 e 4 min; 2) 4 e 8 min; 3) 8 e 12 min; 4) 28 e 32 min; 5) 44 e $48 \mathrm{~min}$; 6) 52 e $56 \mathrm{~min}$; 7 ) 60 e 64 min e 8) efluente original.

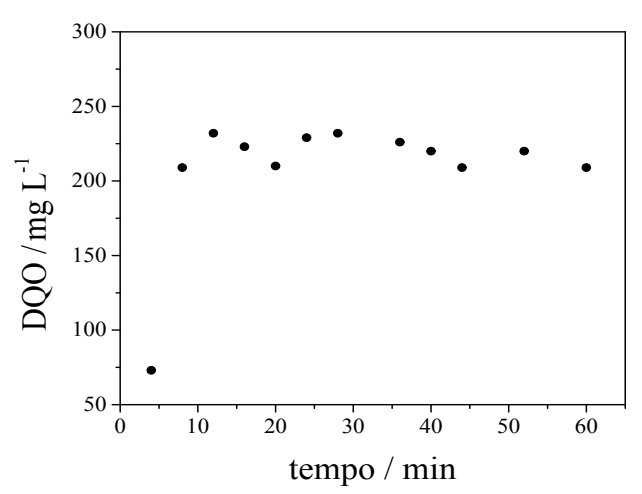

(a)

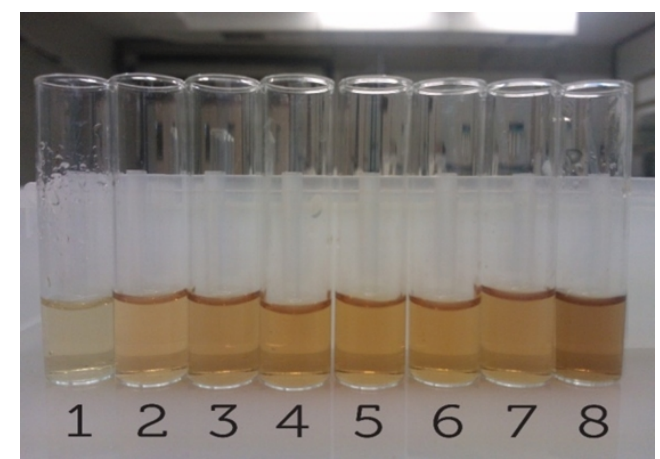

(b)

\section{CONCLUSÕES}

A fuligem gerada da queima do bagaço de cana-de-açúcar se mostrou muito eficaz na remoção de compostos orgânicos, conforme verificado nos experimentos de adsorção de fenol e de compostos orgânicos de um efluente real. Variáveis como a temperatura e o tipo de tratamento da fuligem exerceram influência sobre o processo de adsorção em coluna. Constatou-se que o processo de adsorção é exotérmico uma vez que o aumento da temperatura resultou em uma menor capacidade de adsorção. O tratamento ácido provocou um aumento da capacidade de adsorção quando comparado com a fuligem sem nenhum tratamento. Por outro lado, o tratamento básico da fuligem não é recomendado. $\mathrm{O}$ uso da fuligem para a adsorção de um efluente real mostrou que foi possível remover uma grande quantidade da carga orgânica do efluente, o que foi comprovado visualmente e por análise de DQO. Mesmo apresentando uma DQO muito alta, verificou-se que a coluna de adsorção com fuligem tem grande capacidade de adsorver os compostos orgânicos. O efluente coletado na saída da coluna após 4 minutos de adsorção mostrou que a fuligem foi capaz de remover aproximadamente $67 \%$ da DQO original.

\section{REFERÊNCIAS}

COONEY D.O. Adsorption design for wastewater treatment. Lewis Publishers, New York, 1998.

GOLDEMBERG J., NIGRO F. E.B., COELHO S.T. Bioenergia no estado de São Paulo: situação atual, perspectivas, barreiras e propostas. São Paulo: Imprensa Oficial do Estado de São Paulo. São Paulo, 2008.

RIBEIRO H. Queimadas de cana-de-açúcar no Brasil: efeitos à saúde respiratória. Rev. Saúde Pública, 2008.

TAVARES R. Modelo de São Paulo em Etanol. Secretaria de Agricultura, Secretaria de Energia, Secretaria do Meio Ambiente, Fundação de Amparo à Pesquisa do Estado de São Paulo, 2013. 